\title{
APLICAÇÃO ATENUADA DO CÓDIGO DO CONSUMIDOR E REGULAMENTAÇÃO FRÁGIL DA RELAÇÃO DE CONSUMO PELA LEI DE CONCESSÃ̃O
}

\author{
ATTENUATED APPLICATION OF THE BRAZILIAN CONSUMER CODE AND THE \\ FRAGILITY OF THE CONSUMER'S RELATIONSHIP BY THE CONCESSION LAW
}

Recebimento em 06/02/2021

Aceito em 07/04/2021

\author{
Willams Paixão dos Santos ${ }^{1}$ \\ Hudson Ratis da Costa Vieira ${ }^{2}$ \\ Leonio José Alves da Silva ${ }^{3}$
}

\section{RESUMO}

Este artigo verifica se, de fato, há mitigações ao Código de Defesa do Consumidor (CDC) nas relações de consumo referentes ao fornecimento de energia e analisa o papel desempenhado pela Lei de Concessão nessa esfera. Nesse sentido, analisaram-se os contratos de concessão e adesão de energia elétrica e a compatibilidade deles em relação ao CDC por meio do método jurídico-comparativo de forma a descobrir falhas sistêmicas por meio da identificação de semelhanças e diferenças. Buscou-se identificar mitigações ao CDC nas decisões judiciais segundo o método hipotético-dedutivo e induziu-se algumas conseqüências da frágil regulamentação da relação de consumo pela Lei de Concessão. Revelou-se que, nos contratos de concessão e de adesão de energia, existem aspectos que não se adequam inteiramente ao CDC e que na esfera judicial geralmente há desafios no que se refere à aplicação plenado CDC nos litígios envolvendo concessionária e consumidor, demonstrando a necessidade de uma regulamentação da relação de consumo mais latente pela Lei de Concessão.

Palavras-chave: Direito de Energia. Direito do Consumidor. Lei de Concessão.

\footnotetext{
${ }^{1}$ Graduando em Direito na UFPE

${ }^{2}$ Graduando em Direito na UFPE

${ }^{3}$ Estágio Pós-Doutoral na Università di Pisa. (2019-2020). Estágio Pós-Doutoral na Université Fédérale Toulouse 1 - Capitole. (2017-2017). Projeto de Pesquisa em Cooperação Internacional com a Université Fédérale Toulouse 1 Capitole - França. (2015-2016). Estágio Pós-Doutoral em Direito na Faculdade de Direito da Universidade de Coimbra - Portugal. (2014-2015). Estágio Pós-Doutoral em Direito na Université Montpellier - França. (2014-2015). Estágio Pós-Doutoral em Direito na Università degli Studi di Messina - Itália. (2015). Estágio Pós-Doutoral em Direito na Universidade Federal de Santa Catarina - UFSC (2011). Doutor em Direito - UFPE (2005). Mestre em Direito - UFPE (2000). Bacharel em Direito - UFPE (1998). Professor Associado de Direito Civil da Faculdade de Direito do Recife - UFPE. Professor colaborador de Direito Ambiental do Programa de Desenvolvimento e Meio Ambiente - PRODEMA - UFPE. Ex-Professor Titular de Direito Civil da Universidade Estadual da Paraíba UEPB/CCJ - Campina Grande - PB. Avaliador e parecerista da Revista Direito GV da Fundação Getúlio Vargas FGV/SP. Avaliador e parecerista da Revista de Direito Sanitário do NAP/DISA da USP. Avaliador e parecerista da Revista de Direito da Universidade Federal de Viçosa - UFV. Avaliador e parecerista do Journal of Law and Confllict Resolution- Center for Democratic Studies - University of Haifa - Israel. Avaliador e parecerista da SCIELO - Scientific Eletronic Library Online - FAPESP/CNPq. Membro do Conselho Editorial da Revista de Direito da UFV. Representante do Centro de Ciências Jurídicas - UFPE na Comissão de análise dos enunciados da IV Jornada de Direito Civil do Conselho da Justiça Federal - CJF. Brasília - ESMAFE (2006). Coordenador da Monografia na Graduação em Direito - UFPE (2009). Conselheiro do Colegiado da Graduação em Direito na UFPE (2010-2012, 2014-2016, 2018-2019). Conselheiro da FADE/UFPE (2010-2018). Representante do CCJ na CPPD/UFPE (2016-2017). Representante do Gabinete do Reitor na CPPD/UFPE (2017-2019). Vice-Presidente da CPPD/UFPE (2018-2019). Representante do CCJ na Comissão de avaliação e melhoria dos cursos de Graduação na UFPE (2010). Coordenador do GPID/CNPq - Grupo de Pesquisa Tutela dos Interesses Difusos, com ênfase no Direito consumerista, Direito ambiental, Direito Comparado, Direito das pessoas com necessidades especiais, Direito urbanístico, Direito do idoso, Direito da criança e do adolescente, Direito dos povos indígenas e populações tradicionais e Tutela processual coletiva.
} 


\begin{abstract}
This article verifies if, in fact, there are mitigations to the Consumer Protection Code in the consumption relations related to the energy supply and analyzes the role played by the Concession Law in this sphere. In this sense, the electric energy concession and adhesion contracts and their compatibility with the CDC were analyzed through the legal-comparative method in order to discover systemic failures by identifying similarities and differences. We sought to identify mitigations to the CDC in judicial decisions according to the hypotheticaldeductive method and some consequences of the fragile regulation of the consumption relationship, by the Concession Law, were induced. It was revealed that, in the energy concession and adhesion contracts, there are aspects that are not entirely adequate to the CDC and that in the judicial sphere there are generally challenges regarding the full application of the $\mathrm{CDC}$ in litigation involving concessionaire and consumer, demonstrating theneed for more specific regulation of the consumption relationship by the Concession Law.
\end{abstract}

Keywords: Energy Law. Consumer Law. Concession Law.

\title{
1 INTRODUÇÃO
}

A Constituição Federal, por meio do artigo $5^{\circ}$ inciso XXXII, impõe ao Estado o dever de proteger os direitos e interesses dos consumidores. Diante dessa finalidade, faz-se necessário analisar os problemas concernentes à aplicação do Código do Consumidor no setor de fornecimento de energia elétrica.

A eletricidade é um bem essencial não só à qualidade de vida dos indivíduos, mas também à geração de riquezas no país e ao desenvolvimento da indústria e de outros ramos da economia. Portanto, é fundamental que exista e que se busque o aperfeiçoamento da segurança e da boa prestação de serviços nesse âmbito. Obviamente, uma das formas de possibilitar isso é por meio da proteção da parte frágil da relação de consumo de modo a desencorajar a prestação de um serviço de baixa qualidade. No livro "História do Direito e Pensamento Jurídico em Perspectiva", Francisco Cavalcanti pontua:

"O regramento dos direitos dos usuários de serviços concedidos foi um dos aspectos mais frágeis da lei geral. $\mathrm{O}$ tratamento dado foi genérico e pouco expressivo. De qualquer sorte, embora com algumas atenuações, o CDC (Código de Proteção e Defesa do Consumidor) é aplicado, na maioria das relações, atenuando a omissão do legislador" (CAVALCANTI, 2013).

Nesse sentido, este artigo tem o escopo de analisar a aplicação do CDC no âmbito do fornecimento de energia e investigar essas atenuações na falta de uma regulamentação consumerista efetivamente forte pela Lei de Concessões, esmiuçando os problemas apontados por Cavalcanti por meio da análise de precedentes, contratos e normas setoriais, além de elencar considerações acerca da fragilidade da Lei de Concessões no que tange à regulação da relação de consumo em tal setor econômico.

\section{ANÁllSE dOS CONTRATOS DE CONCESSÃo POR MEIO DA COMPARAÇÃO COM O CÓDIGO DO CONSUMIDOR (CDC)}


O contrato de concessão de energia em questão é disponibilizado na página virtual da Agência Nacional de Energia Elétrica (ANEEL) ${ }^{4}$. Quanto à natureza do instrumento, trata-se de um "contrato administrativo mediante o qual o Poder Público transfere ao concessionário, pessoa jurídica de direito privado, o exercício de determinados serviços para que os execute em seu nome, arcando com o risco do empreendimento, mas sob a constante fiscalização do poder concedente, nos termos da lei, do contrato e do respectivo edital de licitação."5 Mário Mazagão, ao explicar a natureza desta espécie de contrato, ressalta a sua qualidade onerosa ${ }^{6}$, isto é, ele traz benefícios e ônus para ambas as partes ${ }^{7}$.

Cabe ressaltar, também, que a concessão é uma das alternativas que dispõe o Estado para formalizar a concepção contemporânea de Estado que pressupõe a participação da chamada Sociedade Civil, especificamente no tocante à prestação de utilidades necessárias à satisfação imediata da dignidade humana, como a energia elétrica. Corrobora isso, Rosa, ao defender que o acesso à energia elétrica é uma manifestação do direito ao mínimo existencial, assim, designando serviços públicos essenciais de prestação continuada ${ }^{8}$. Sabendo-se dessas informações, pode-se iniciar a análise.

A Subcláusula Terceira da primeira cláusula referente ao contrato de concessão de distribuição dispõe que não confere à concessionária direito de exclusividade relativamente aos consumidores de energia elétrica que, por força da Lei $\mathrm{n}^{\circ} 9.074 / 95$, possam adquirir energia elétrica de outro fornecedor. Nesse sentido, está em conformidade com o artigo 170 da Constituição Federal e o art. $4^{\mathrm{o}}$ do Código do Consumidor. Isso porque a harmonização da relação de consumo e a concretização dos interesses dos consumidores devem estar de acordo com os princípios nos quais se funda a ordem econômica tais como o da livre concorrência, que é claramente mencionada por essa subcláusula e por esses artigos. Essa conformidade é totalmente pertinente uma vez que a concorrência impulsiona os produtores a atingir melhores resultados ao destinarem seus esforços em busca de produtividade. Por consequência disso, a economia busca dinamismos produtivos e os consumidores conseguem se beneficiar disso, pois há o acesso a novos produtos cujos preços são mais baixos. Argumentam, nesse sentido, Ejan Mackaay e Stéphane Rousseau ao mostrarem que, de acordo com os princípios da microeconomia, o monopólio provoca transferência de riqueza dos consumidores para o monopolista, gerando perda para aqueles ${ }^{9}$.

Apesar de nesse ponto haver a conformidade entre o Contrato de Concessão e o CDC, a natureza da concessão de distribuição elétrica traz à tona algumas questões que precisam ser respondidas: Quem se beneficia dessa cláusula? O setor energético não seria enquadrado como atividade monopolista? Essa subcláusula é efetiva? Segundo a Portaria 465/2019, atualmente, o limite de carga mínima para compra de energia de qualquer fornecedor no ambiente de contratação livre é $2500 \mathrm{KW}$ e estipula-se que em 2023 os consumidores com carga igual ou superior a $500 \mathrm{KW}$, atendidos em qualquer tensão, poderão optar pela compra de energia elétrica

${ }^{4}$ Brasil. CONTRATO DE CONCESSÃO DE DISTRIBUIÇÃO No 26/2000. Para distribuição de energia elétrica que celebram a União e a Companhia Energética de Pernambuco - CELPE. Agência Nacional de Energia Elétrica. Disponível

em:https://www.aneel.gov.br/documents/10184//15062917//Contrato+de+Concess\%C3\%A3o.pdf. Acesso em: 14 nov. 2020.

${ }^{5}$ LENZ, Carlos Eduardo Thompson Flores. O contrato de concessão de serviço público. A\&C-Revista de Direito Administrativo \& Constitucional, v. 8, n. 33, p. 161-192, 2008.

${ }^{6}$ MAZAGÃO, Mário, Natureza Jurídica da Concessão de Serviço Público. Revista de Doutrina da Quarta Região, São Paulo, 1933, p. 101.

${ }^{7}$ JUSTEN FILHO, Marçal. As diversas configurações da Concessão do serviço público. Revista de direito público da economia, v.1, p. 95-136, 2003.

${ }^{8}$ ROSA, Taís Hemannda.O acesso à energia elétrica como manifestação do direito ao mínimo existencial: uma análise com ênfase na dimensão defensiva do direito de acesso à energia. Rio Grande do Sul: [S.n.],

2016. Disponível em: https://repositorio.pucrs.br/dspace/handle/10923/8511. Acesso em: 17 dez. 2020.

${ }^{9}$ Rousseau, E. M. Análise Econômica do Direito . São Paulo : Atlas, 2015. p. 108. 
a qualquer concessionária, permissionário ou autorizado de energia elétrica do Sistema Interligado Nacional ${ }^{10}$. Portanto, os pequenos consumidores- os consumidores em uma situação econômica mais vulnerável - não usufruem dessa opção. Esses pequenos consumidores de energia estão enquadrados no mercado cativo no qual o consumidor contrata energia compulsoriamente via a distribuidora da região em que está. No mercado cativo, as tarifas de consumo são fixadas pela Agência Nacional de Energia Elétrica (ANEEL) e não podem ser negociadas. Nesse sentido, a ANEEL adota o modelo regulatório price cap (preço teto) com fator $\mathrm{X}$, para o reajuste tarifário. Nesse sentido o price cap pode ser mais bem explicitado da seguinte forma:

É o que busca exatamente o price cap com fator X: eficiência produtiva e modicidade tarifária. $\mathrm{O}$ regulador elege um indicador de preços para $\mathrm{o}$ reajuste tarifário, que em concorrência perfeita seria o "preço de mercado" sob o qual o produtor não tem influência. Ou seja, o produtor é tomador de preço. Aqui, o regulador também é tomador de preço ao não conseguir influenciar esse indicador inflacionário. Tal indicador pode ser um índice geral de preços (atacado ou varejo), ou ainda um índice setorial composto normalmente por uma cesta de índices que reflita mais de perto a evolução dos custos do setor regulado em questão. (NUSDEO, et al., 2010, p. 87)

Então, como é possível notar, a distribuidora concedida é um monopólio natural regulamentado pelo Estado. Essa regulamentação tem por finalidade evitar os abusos de poder característicos de monopólios cuja principal característica é o aumento sucessivo de preços em busca do lucro máximo, lesando, pois, o consumidor. Por consequência, como a subcláusula $3^{\circ}$ da $1^{\circ}$ cláusula ainda não incide sobre o mercado energético quando ele diz respeito aos consumidores de baixa potência, a regulamentação da ANEEL visa à anulação ou, pelo menos, a mitigação dos efeitos lesivos resultantes do monopólio. Ou seja, para os consumidores mais vulneráveis não há oportunidade de escolhas realmente eficientes. Corrobora Milton Friedman a essa conclusão ao defender que existe apenas uma escolha entre três demônios: o monopólio privado desregulamentado, o monopólio privado regulamentado pelo Estado e a produção estatal (FRIEDMAN, 1962).

Indo adiante, a subcláusula primeira da segunda cláusula também tem uma notável conformidade com o já mencionado Art. $4^{\circ}$ do CDC porqueela atende ao princípio da ação governamental, já que faz valer a finalidade de proteção do consumidor por meio da garantia de produtos e serviços de acordo com os padrões de qualidade. Essa subcláusula atende ainda a uma série de outras finalidades postas pelo direito do consumidor tais como assegurar a saúde e a segurança. Diante disso, ela promove a concretização do art. $8^{\circ}$ do $\mathrm{CDC}$, que se preocupa com o bem tutelado mais importante no direito do consumidor: a vida do consumidor. Isso porque essa subcláusula estabelece o compromisso de utilizar equipamentos de qualidade como forma de assegurar a segurança e a saúde.

Não é novidade que a energia elétrica fornece riscos que são próprios de sua natureza. Por exemplo, uma descarga atmosférica que incide sobre o solo fornece perigo uma vez que isso pode resultar em uma diferença de potencial no solo capaz de eletrocutar um homem que esteja andando nos arredores. Isso é denominado como tensão de passo, definida por Sólon Medeiros como a diferença que pode se manifestar entre dois pontos da superfície da terra, separados por

${ }^{10}$ BRASIL. Portaria $n^{\text {o }}$ 465, de 12 de dezembro de 2019. DiárioOficial [da] República Federativa do Brasil, Poder Executivo, Brasília, DF, 16 dez. 2019. Seção 1, p. 156 


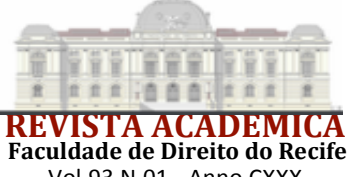

Vol.93 N.01 - Anno CXXX

uma distância igual ao passo de uma pessoa (MEDEIROS, 1981). Nesse sentido, um rompimento ou queda de um condutor do sistema de distribuição devido à má qualidade de um material, por exemplo, também pode fornecer risco pela tensão de passo a depender da tensão do condutor energizado e em contato com o solo. Portanto, é possível notar que o comprometimento com o uso de dispositivos e tecnologias adequadas é imprescindível para o fornecimento de um serviço de qualidade e garantia da saúde e segurança do consumidor, estando tal subcláusula em harmonia com os princípios consumeristas.

A Subcláusula Décima Primeira (da segunda cláusula) diz que a concessionária deverá manter registros das solicitações e reclamações dos consumidores de energia elétrica, de acordo com os prazos legais e demais condições estabelecidas no Anexo III do contrato de concessão. Nesse anexo fica registrado que os indicadores a serem acompanhados e que não estarão sujeitos a penalidades serão a Pesquisa de Opinião Pública, Segurança e Perdas de Energia Elétrica. Em semelhança a essa ideia, o Art. 44 do CDC diz que os órgãos públicos de defesa do consumidor manterão os cadastros de reclamação atualizados.

Nesse caso, a ANEEL, embora não seja um órgão cujo objetivo seja especialmente a defesa do consumidor, acaba por desempenhar uma função comparável nessa situação visto que é ela a responsável por observar e controlar esses dados e indicadores. Contudo, há problemas: o artigo 44 do CDC dá ênfase a esse arquivamento e divulgação porque se almeja a informação dos consumidores de modo a orientá-los. Isso fica claro na própria redação desse artigo que dispõe em seu primeiro parágrafo que é facultado o acesso às informações lá constantes (constantes nos órgãos de defesa do consumidor) para a orientação e consulta por qualquer interessado. Note que não há essa mesma eficácia no registro das solicitações e reclamações dos usuários pela concessionária porque se trata de um monopólio regulado e nesse sentido há.

Em um mercado de concorrência a divulgação da opinião pública negativa seria por si só uma penalidade visto que ou a concorrência poderia usar esses dados comparativamente em publicidades, convencendo os consumidores a aderirem a seus produtos, ou os consumidores poderiam consultá-los individualmente, gerando uma queda na demanda pelos produtos da empresa exposta. Note, que, para o setor elétrico, essa ideia não se aplica pois, em tese, não existe concorrência nesse âmbito. Então, o único modo de tornar essa subcláusula útil efetivamente é pela imposição de penalidades pela ANEEL de acordo com essas reclamações dos usuários. Logicamente, esse raciocínio de que seria eficiente tornar as opiniões públicas como passíveis de implicar penalidades parte da premissa de que existiria um controle sobre a fundamentação das opiniões que comporiam o índice no sentido de exclusão das opiniões claramente descabidas.

Ademais, o contrato de concessão exclui como passíveis a penalidades os índices de segurança tais como o NACTER (número de acidentes com terceiros envolvendo a rede elétrica e demais instalações) e o NMOTER (número de mortes decorrentes de acidentes com terceiros envolvendo a rede elétrica). Note que em uma situação de imposição de penalidades a partir desses índices, que são numéricos, a concessionária seria impelida a avançar e aprimorar ainda mais a segurança das instalações. Nesse sentido, nota-se que há uma despreocupação com o nível de risco ao qual está exposta a população em geral, que são os consumidores. Portanto, há certa inconformidade da subcláusula $11^{\circ}$ da $2^{\circ}$ cláusula com os fins de segurança e saúde estabelecidos no direito do consumidor, posto que há omissão da subcláusula em relação à busca dessas finalidades e, a partir disso, uma certa redução no controle da ANEEL sobre as concessionárias.

Art. 106. O Departamento Nacional de Defesa do Consumidor, da Secretaria Nacional de Direito Econômico - MJ, ou órgão federal que venha substituí-lo, é organismo de coordenação da política do Sistema Nacional de Defesa do Consumidor, cabendo-lhe: ... IX - incentivar, inclusive com recursos financeiros e outros programas especiais, a 


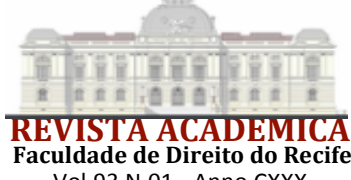

Vol.93 N.01 - Anno CXXX

formação de entidades de defesa do consumidor pela população e pelos órgãos públicos estaduais e municipais. (BRASIL, 1990).

Nesse sentido, o contrato de concessão se alinha, de certa forma, ao Art. 106 do CDC. Isso porque, por meio da sua subcláusula Décima Quinta (da segunda cláusula), é estabelecida a obrigatoriedade de manutenção do conselho dos consumidores pela concessionária mesmo esta não sendo órgão público - como se vê a seguir:

\section{A CONCESSIONÁRIA organizará e manterá em permanente \\ funcionamento o Conselho de Consumidores, integrado por representantes das diversas classes de consumidores, de caráter consultivo e voltado para orientação, análise e avaliação do serviço e da qualidade do atendimento prestado pela CONCESSIONÁRIA, bem como para formulação de sugestões e propostas de melhoria do serviço. (BRASIL, 2000)}

Então, nota-se que, nesse caso, há mais do que o incentivo: o Estado estabelece a obrigação da concessionária em manter tal conselho cujas funções são principalmente de consulta e avaliação de serviços. Ou seja, por meio do estabelecimento de um conselho cujos interesses se opõem ao da concessionária, o Estado tenta reforçar o princípio consumerista de harmonização dos interesses. Entretanto, apesar de pertinente, não se pode enquadrar esse conselho como uma entidade de defesa do consumidor, pois, como dito pela ANEEL, os conselhos são órgãos sem personalidade jurídica, de caráter consultivo, formado por representantes das principais classes das unidades consumidoras, com a incumbência de opinar sobre assuntos relacionados à prestação do serviço público de energia elétrica, conforme definido na Resolução 451/2011.

Portanto, a representatividade do conselho bem como sua eficácia são questionáveis, restando-nos dizer que aí há uma quase concretização da harmonização de interesses. Isso porque o conselho tem apenas um caráter consultivo e opinativo além de apresentar um modelo de representatividade limitado e que não estabelece direta relação com as massas, não sendo cumprida, portanto, a determinação do mencionado art. 116 do CDC referente ao incentivo, inclusive com recursos financeiros e outros programas especiais, da formação de entidades de defesa do consumidor pela população e pelos órgãos públicos estaduais e municipais.

\section{ANÁliSE dO CONTRATO DE ADESÃO ATRAVÉS DE UMA ABORDAGEM COMPARATIVA EM RELAÇÃO AO CDC}

O contrato de adesão nasce da própria sociedade massificada, que torna inviável a discussão dos termos da contratação de modo individual. Como pontua GOMES, os contratos de adesão são aqueles nos quais uma das partes se obriga a aceitar as cláusulas estabelecidas pela outra, aderindo a uma situação contratual que se encontra definida em todos os seus termos 11 . Destacaremos, nesse sentido, como características do contrato de adesão as expostas por Cláudia Lima Marques: sua pré-elaborarão unilateral, sua oferta uniforme e de caráter geral, para um número ainda indeterminado de futuras relações contratuais e seu modo de aceitação, onde o consentimento se dá por simples adesão à vontade manifestada pelo parceiro contratual economicamente mais forte ${ }^{12}$. Em razão disso, as cláusulas contratuais desse instrumento devem ser interpretadas de forma mais benéfica ao consumidor conforme dispõe o próprio CDC.

\footnotetext{
${ }^{11}$ GOMES, Rogério Zuel. A nova ordem contratual: pós-modernidade, contratos de adesão, condições gerais de contratação, contratos relacionais e redes contratuais. Revista de Direito do Consumidor,v. 58, n. 58, 2006.

${ }^{12}$ Marques, C. L. Contratos no Código de Defesa do Consumidor. São Paulo: Revista dos Tribunais, 2019.
} 


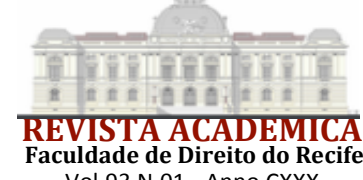

Vol.93 N.01 - Anno CXXX

O contrato analisado diz respeito à Companhia de Eletricidade do Estado da Bahia ${ }^{13}$ e se refere aos consumidores de baixa tensão, grupo mais numeroso e mais vulnerável, podendo ser consultado na página de cada concessionária de energia. Nesse contrato, elenca-se como obrigação da concessionária uma série de pontuações acercada obrigação de informar. Entretanto, as obrigações impostas, nesse sentido, mostram-se insuficientes à concretização plena da situação estipulada pelo Art. 31 do CDC:

Art. 31. A oferta e apresentação de produtos ou serviços devem assegurar informações corretas, claras, precisas, ostensivas e em língua portuguesa sobre suas características, qualidades, quantidade, composição, preço, garantia, prazos de validade e origem, entre outros dados, bem como sobre os riscos que apresentam à saúde e segurança dos consumidores. Parágrafo único. As informações de que trata este artigo, nos produtos refrigerados oferecidos ao consumidor, serão gravadas de forma indelével. (BRASIL, 1990)

Essa insuficiência pode ser notada a partir do momento em que o contrato de adesão não estipula como obrigação informar sobre outras tarifas não convencionais, que podem ser vantajosas ao consumidor. No grupo B - grupo que engloba os consumidores de baixa tensão e sobre o qual incide o contrato aqui sinalizado-, há a opção não convencional pela tarifa branca. Nesse tipo de tarifa, aplicam-se três postos tarifários: ponta, intermediário e fora de ponta. Resume-se isso da seguinte forma: na maior parte do tempo, a tarifa é mais barata do que a convencional e esse baixo custo é válido para qualquer horário dos feriados e finais de semana. Entretanto, nos horários de maior consumo, a energia fica bem mais cara, ou seja, dependendo do perfil do consumidor ela pode ser mais vantajosa caso os consumidores costumem não utilizar muita energia nos horários em que há maior demanda geral por energia.

Sabe-se que a situação econômica e educacional da população brasileira é, de modo geral, bastante frágil. Diante disso, seria de fundamental importância informar de forma clara e didática ao consumidor sobre essa opção. Como vimos o Art. 31 do CDC menciona de forma expressa a obrigação do fornecedor em informar sobre os preços, mas, nessa situação, evidencia-se certa "ocultação" de preço, uma vez que a maioria dos consumidores de baixa tensão não tem conhecimento sobre a existência de uma tarifa diferenciada. Isso porque eles são vulneráveis do ponto de vista econômico e social para adquirirem a informação de modo autônomo. Portanto, embora o contrato de adesão estipule pertinentemente o dever da concessionária em informar alguns determinados pontos, deve-se expandir a informação a outras esferas, visando a um avanço na conformidade com Art. 31 do CDC. Nesse sentido, estipular a obrigação da concessionária em informar os consumidores sobre tarifas não convencionais se faz imprescindível para que haja a escolha livre do consumidor de forma a não o onerar pela falta de acesso à informação e, portanto, avançando rumo a uma maior conformidade em relação ao CDC

Outro direito do consumidor estipulado pelo contrato de adesão é o de Receber energia elétrica em sua unidade consumidora, nos padrões de tensão e de índices de continuidade estabelecidos. Nesse sentido, o contrato de concessão desempenha importante papel ao esmiuçar tais padrões. No $\mathrm{CDC}, \mathrm{o}$ Art. $4^{\circ}$ já mencionado diz que se deve atender à garantia dos produtos e serviços com padrões adequados de qualidade, segurança, durabilidade e desempenho. Entretanto, não é o CDC que delimita quais os padrões adequados, mas o contrato de concessão por meio de padrões como os índices de tensão e de continuidade. Logicamente, o CDC não iria esmiuçar essas informações, pois ele é aplicado em todas as relações de consumo, cada uma

${ }^{13}$ Disponível em: http://www.agersa.ba.gov.br/wp-content/uploads/2021/01/CONTRATO-COELBA.pdf. Acesso em: 12 ago. 2020. 
delas apresentando peculiaridades. Portanto, o CDC incide em uma esfera de mercado mais ampla, tornando-o altamente eficiente e aplicável em toda relação de consumo independentemente de suas peculiaridades, já que nele existe uma série de princípios norteadores de caráter generalista.

Essa situação, de certo modo, justifica a análise feita do contrato de concessão à luz do CDC: mesmo que o CDC não incida sobre a relação de concessão, a relação de concessão influencia a relação de consumo no caso do fornecimento de energia. Isso porque, como já exposto, o contrato de concessão chega a esmiuçar obrigações impostas pelo contrato de adesão. Nesse sentido, o contrato de concessão regula não só a relação de concessão, mas também a relação entre consumidor e concessionária.

\section{LITÍGIOS NO TRIBUNAL DE JUSTIÇA DE PERNAMBUCO REFERENTES AOS CONFLITOS ENTRE CONSUMIDOR E DISTRIBUIDORA DE ENERGIA}

A fim de coletar dados acerca dos conflitos entre consumidor e distribuidora de energia utilizou-se a ferramenta de busca de precedentes do TJPE ${ }^{14}$. Para essa coleta usou-se as palavras chaves "ANEEL" "fornecimento de energia" "CDC" "resolução ANEEL" nas mais diversas combinações para obter o número de vezes em que o $\mathrm{CDC}$ e as normas setoriais da ANEEL eram referenciadas.

Analisando-se esses dados, percebeu-se que, nos últimos dois anos, aumentou o número de sentenças referentes ao fornecimento de energia. Especialmente, nos últimos 4 (quatro) meses, a referência exclusiva a normas setoriais quase triplicou nas sentenças de conflitos entre consumidores e distribuidora de energia, o que pode ser explicado pela determinação da ANEEL de que, durante a pandemia do COVID-19, seria proibido o corte de energia para a baixa renda.Isso porque as normas setoriais são de competência da ANEEL, desse modo, a determinação citada é uma espécie daquelas. Além disso, usando a pandemia como parâmetro, antes dela, o menos provável era que a decisão tivesse como fundamento as regras setoriais da ANEEL juntamente com o CDC, sendo mais provável, nos meses analisados de 2019, que fossem usadas como fundamento exclusivamente as normas setoriais da ANEEL e, nos primeiros meses de 2020, unicamente nas normas do Código do Consumidor. Ademais, durante os meses de março e maio de 2020, devido à pandemia citada, algumas concessionárias de energia elétrica suspenderam a leitura presencial do consumo e calcularam o valor segundo a média dos últimos 12 meses, o que pode ser injusto, uma vez que muitos estabelecimentos comerciais funcionaram menos em razão do isolamento social. Sobre isso, o Procon-SP afirmou que os consumidores que se sentiram prejudicados deveriam buscar a esfera judicial. Assim, nota-se mais um desafio na garantia dos direitos dos consumidores de energia durante a pandemia que pode afetar o número de conflitos judicialmente postos.

Portanto, pode-se concluir que a jurisprudência mais recente reflete um contexto bastante específico em razão da pandemia deste ano. Apesar disso, dados mais distantes, como os de 2019, apontam que se costumava decidir com base nas normas setoriais com mais frequência do que com o CDC (mais de 200 sentenças apuradas).

\section{NÃO EFETIVAÇ̃̃O DOS PRINCÍPIOS CONSUMERISTAS E INCIDÊNCIA DA FRAGILIDADE DAS NORMAS SETORIAIS NAS RELAÇÕES DE CONSUMO DO FORNECIMENTO DE ENERGIA}

\footnotetext{
${ }^{14}$ Disponível em: http://www.tjpe.jus.br/consultajurisprudenciaweb/xhtml/consulta/consulta.xhtml. Acesso em: 30 ago. 2020.
} 
Nas decisões coletadas conforme mencionado anteriormente, constatou-se o TOI, principalmente entre os meses de maio a julho de 2020, como um dos elementos responsáveis pelo número expressivo de litigâncias na esfera do fornecimento de energia. O TOI (Termo de Ocorrência e Inspeção) é um documento exemplificado e mencionado na resolução 414/2010 da ANEEL e que, às vezes, é considerado pelo TJPE como um elemento de verificação unilateral. Ou seja, a falta consenso sobre a aceitabilidade desse documento demonstra um problema de insegurança jurídica. Com isso, o TOI, em alguns casos, representou não só uma incongruência com as normas setoriais, mas, de certa forma, com o CDC. Nesse sentido está o processo 0004760-91.2019.8.17.2001/PE:

1. Constitui poder-dever das concessionárias inspecionarem os equipamentos de medição periodicamente, especialmente quando se suspeita da ocorrência de fraude e desvio de energia. 2. Segundo as normas editadas pela ANEEL, na Resolução no 414/2010, o consumidor torna-se responsável pela adequação técnica e segurança das instalações internas das unidades consumidoras, o que engloba os danos e defeitos nestas decorrentes da má utilização e conservação das instalações ou do uso inadequado de energia. 3. O Termo de Inspeção e Ocorrência (TOI), configura respeito da companhia energética ao contraditório. Com efeito, a Celpe fez prova nesse sentido juntando o documento. 4. Por fim, a perícia não ocorreu simplesmente porque a autora não solicitou, nem no momento da inspeção, tampouco no momento de procedimento administrativo... ACORDAM os Desembargadores do Egrégio Tribunal de Justiça que compõem a $3^{\mathrm{a}}$ Câmara Cível, em dar provimento ao recurso, por unanimidade, na conformidade do relatório, do voto e da ementa. (BRASIL, 2020).

Essa decisão representa uma oposição à efetivação dos princípios consumeristas, estando, também, em desacordo com a súmula $\mathrm{n}^{\circ}$ 13/TJPE, a qual estabelece ser abusiva a suspensão do fornecimento de energia elétrica quando motivada pelo inadimplemento de débito unilateralmente arbitrado pela concessionária ${ }^{15}$. Isso porque o TOI se revela estruturalmente frágil do ponto de vista da imparcialidade, visto que é construído unilateralmente pelos próprios membros da concessionária de energia. Nesse sentido, o TJRJ, como aponta a Súmula 256, diz que o termo de ocorrência de irregularidade, emanado de concessionária, não ostenta o atributo da presunção de legitimidade, ainda que subscrito pelo usuário (BRASIL, 2012).

Também se desrespeita, como mencionado, o direito do consumidor, visto que o TOI por si só representa uma desarmonização de interesses. Isso porque, conforme falado, ele é um instrumento de prova unilateral. Embora a resolução dê espaço ao contraditório, ao permitir que o usuário do serviço solicite perícia técnica, deve-se levar em consideração que essa solicitação pressupõe um conhecimento que a maior parte dos consumidores não possui em virtude dos baixos indicadores sociais e econômicos do país. Devido a isso o TOI passa a ser uma prova ineficiente e, inclusive, invalidada pelas normas setoriais quando não acompanhado de perícia técnica, como bem aponta a resolução 414/2010 da ANEEL:

“Art. 129. $\mathrm{Na}$ ocorrência de indício de procedimento irregular, a distribuidora deve adotar as providências necessárias para sua fiel

\footnotetext{
${ }^{15}$ BRASIL. Tribunal de Justiça de Pernambuco.Súmula TJPE no 013. Disponível em:

https://www.tjpe.jus.br/documents/10180/0/-/08b9a5ff-0232-469a-bd24-d621219abf08. Acesso em: 18 dez. 2020 .
} 
caracterização e apuração do consumo não faturado ou faturado a menor. I - Emitir o Termo de Ocorrência e Inspeção - TOI, em formulário próprio, elaborado conforme Anexo V desta Resolução; II - solicitar perícia técnica, a seu critério, ou quando requerida pelo consumidor ou por seu representante legal; III - elaborar relatório de avaliação técnica, quando constatada a violação do medidor ou demais equipamentos de medição, exceto quando for solicitada a perícia técnica de que trata o inciso II" (BRASIL, 2020).

Com isso, vê-se que a concessionária tem o dever de solicitar perícia técnica, independentemente do requerimento do consumidor. Além disso, a partir da constatação de insuficiência do TOI, dever-se-ia ressarcir o consumidor em um valor equivalente ao cobrado pela concessionária. Isso porque o Supremo Tribunal de Justiça (STJ) decidiu também, conforme Resp. 1.645.589-MS, julgado em 04/02/2020 ${ }^{16}$, pela aplicação do artigo 940 do CC para relação de consumo:

Art. 940. Aquele que demandar por dívida já paga, no todo ou em parte, sem ressalvar as quantias recebidas ou pedir mais do que for devido, ficará obrigado a pagar ao devedor, no primeiro caso, o dobro do que houver cobrado e, no segundo, o equivalente do que dele exigir, salvo se houver prescrição. (BRASIL, 2002)

Nesse sentido, em busca de uma conformidade com Art. 927 do CPC, o TJPE deve observar o Art. 940 do CC nas suas decisões referentes a cobranças indevidas através de TOI, que, por si só, é um mecanismo de comprovação unilateral. Contudo essa conformidade não se observa, como exposto no processo 0008764-77.2016.8.17.2810/PE:

2. A concessionária não trouxe aos autos a perícia técnica desenvolvida pelo órgão metrológico ou entidade por ele delegada ou terceiro legalmente habilitado com vistas a examinar e certificar o desvio de energia atribuído ao domicílio do apelado, portanto, agiu de forma contrária aos parâmetros sedimentados na legislação e nos precedentes mencionados no presente julgamento. 3. Manutenção do valor da condenação por dano moral estipulada pelo juízo de primeiro grau - $\mathrm{R} \$$ $3.000,00$ (três mil reais), porquanto, observa o princípio da razoabilidade que, pelas peculiaridades do caso, guarda legítima correspondência com o transtorno que foi causado ao autor, como também atende a culpa da concessionária, para evitar a repetição de episódios semelhantes. 4. Sentença mantida. Recurso improvido. (BRASIL, 2020)

${ }^{13}$ BRASIL. Superior Tribunal de Justiça. Recurso Especial no 1645589-MS. Recorrente: HSBC BANK Brasil S.A. Recorrido: Nelida Doroteia Ormay. Relator: Ricardo Villas Bôas Cueva. Brasília, 04 de fevereiro de 2020. Disponível

em:https://processo.stj.jus.br/processo/pesquisa/?termo=Resp.+1.645.589\&aplicacao=processos.ea\&tipoPesquisa=ti poPesquisaGenerica\&chkordem=DESC\&chkMorto=MORTO. Acesso em: 12 nov. 2020. 
Nesse processo, o TOI, por si só, foi devidamente considerado um mecanismo de prova unilateral, mas o Art. 940 do Código Civil (CC) não foi devidamente observado. Portanto, uma vez que a cobrança embasada apenas no TOI é considerada insuficiente, deve o consumidor ser ressarcido, também, pela quantia equivalente ao indevido valor cobrado pela concessionária, visto que foi cobrada uma quantia em excesso referente aos meses anteriores, posto que a cobrança proveniente de possível furto refere-se, obviamente, a meses passados já pagos havendo uma cobrança em excesso. Portanto, esse não é um caso de mitigação do CDC porque ele não estabelece a obrigação de ressarcimento nos casos em que o valor cobrado indevidamente não foi pago, como menciona o Art. 42 CDC:

Na cobrança de débitos, o consumidor inadimplente não será exposto a ridículo, nem será submetido a qualquer tipo de constrangimento ou ameaça. Parágrafo único. O consumidor cobrado em quantia indevida tem direito à repetição do indébito, por valor igual ao dobro do que pagou em excesso, acrescido de correção monetária e juros legais, salvo hipótese de engano justificável. (BRASIL,1990)

Contudo, é um caso de mitigação e inconsideração no sentido da devida proteção da parte frágil da relação de consumo, que, no caso exposto e em outros, deveria ser mais bem recompensado pelos danos provenientes de uma cobrança indevida, acompanhada, ainda, de corte de um serviço essencial. Portanto, enquanto no caso da aceitabilidade do TOI há um desrespeito aos princípios consumeristas, na reparação por valor indevidamente cobrado de furto de energia, visualiza-se uma desconsideração com a determinação de observância ao Art. 940 do $\mathrm{CC}$ e, portanto, um encargo de prejuízo à proteção plena do consumidor.

Verificando-se as decisões também dos meses de maio a julho de 2020, identificou-se outra problemática que se refere à mitigação dos princípios consumeristas. Essa problemática pode ser observada em processos em que não se observou as condições de vulnerabilidade dos consumidores como a APELAÇÃO CÍVEL 0002722-91.2018.8.17.2470/PE no qual normas setoriais e cláusulas contratuais foram corretamente observadas, mas faltou observação à aplicação do CDC no que se refere ao seu Art. $39{ }^{17}$ a seguir:

Art. 39. É vedado ao fornecedor de produtos ou serviços, dentre outras práticas abusivas: (...) IV - prevalecer-se da fraqueza ou ignorância do consumidor, tendo em vista sua idade, saúde, conhecimento ou condição social, para impingir-lhe seus produtos ou serviços; V- exigir do consumidor vantagem manifestamente excessiva. (BRASIL, 1990)

Nesses processos, alegou-se corte indevidamente realizado sem aviso prévio para fins de reparo, porém foi comprovado o aviso prévio por meio de e-mail/internet. Nesse sentido, seria essencial levar em consideração os aspectos sócio econômicos do consumidor e da concessionária, pois em um país debilitado como o Brasil, o acesso a internet é limitado. Com isso, a decisão recorrida nesse processo se aproxima mais do CDC:

\footnotetext{
${ }^{17}$ BRASIL. Tribunal de Justiça de Pernambuco. Apelação cível no 0002722-91.2018.8.17.2470. Apelante: Maria de Fatima Pereira dos Santos. Apelado: CELPE. Relator: Agenor Ferreira de Lima Filho. Recife, 08 de junho de 2020. Disponível em: https://srv01.tjpe.jus.br/consultaprocessualunificada/processo/. Acesso em: 15 nov. 2020.
} 
DECISÃO RECORRIDA: - Dispositivo recorrida constante no ID 7575031 dos autos, ipsis litteris: “(...). Para tanto, deve avaliar se houve ou não consequências mais sérias à vida ou à saúde do consumidor, a capacidade econômica de quem vai reparar, na situação em apreço a quantidade de ações distribuídas no mesmo sentido e a quantidade de práticas ilícitas praticadas em face de um mesmo consumidor e de outros na mesma situação. Diante dessas considerações, entendo justo e equitativo fixar o valor da reparação compensatória por danos extrapatrimoniais em $\mathrm{R} \$ 1.800,00$ (hum mil e oitocentos reais). Ante o exposto, por tudo o que até aqui bem analisei, JULGO PARCIALMENTE PROCEDENTE o pedido formulado por MARIA DE FATIMA PEREIRA DOS SANTOS no sentido de CONDENAR a ré, CELPE - GRUPO NEOENERGIA CIA ENERGÉTICA DE PERNAMBUCO. (BRASIL, 2020)

Portanto, a decisão em primeira instância mostra-se mais propensa a conformar o Art. 39 do CDC porquanto leva em consideração a vulnerabilidade do consumidor como parâmetro de decisão. Isso porque, apesar desse artigo não abordar de forma direta o âmbito de incidência desse caso, sabe-se que o CDC funciona como princípios norteadores de quaisquer relações de consumo. Logo, estendendo essa norma a esse caso, observa-se que a veiculação de informação de suspensão de serviço em esferas limitadas de comunicação é, de certa forma, um prevalecimento da concessionária diante da fraqueza ou ignorância do consumidor, pois aquela livremente opta sobre o veículo que utilizará, provavelmente, optando por aquele com menor custo, havendo uma despreocupação com um serviço de qualidade no âmbito da informação.

Nessa questão, a concessionária de energia também é prejudicada porquanto seguiu devidamente cláusulas contratuais. No caso, a cláusula terceira do contrato de adesão que lista, como direito do consumidor, ser informado sobre a ocorrência de interrupções programadas, por meio de jornais, revistas, rádio, televisão, ou outro meio de comunicação, com antecedência mínima de 72 (setenta e duas) horas. Portanto, existe um problema em relação a eficiência da cláusula. Isso porque, a depender do nível social do consumidor, ele não terá acesso à informação do desligamento por indisponibilidade desses veículos. Nesse sentido, para que não haja danos nem ao consumidor nem a concessionária, seriam necessárias alterações nas redações do contrato de adesão. Ou seja, poder-se-ia resolver isso por meio de uma delimitação mais clara do veículo de informação, obrigando-se a concessionária a enviar o aviso por escrito aos consumidores identificados como vulneráveis socialmente.

Outro problema identificado refere-se à quantidade de meses levado em consideração no cálculo de dívida proveniente de consumo regular. Segundo entendimento jurisprudencial. Como aponta o STJ, conforme Resp. 1.412.433-RS ${ }^{18}$, é possível o corte administrativo do fornecimento do serviço de energia elétrica pelo inadimplemento do consumo recuperado correspondente ao período de 90 (noventa) dias anterior à constatação da fraude, contanto que executado o corte em até 90 (noventa) dias após o vencimento do débito (Brasil, 2018). Com isso, o STJ afirmou o entendimento sobre a necessidade de limitação temporal para a cobrança administrativa em que pode ser cobrada a energia não medida dos últimos três meses.

Esse entendimento é pertinente visto que a concessionária se incube do dever de não só fornecer o serviço, mas também de fiscalizar adequada e periodicamente o sistema de controle de

\footnotetext{
${ }^{18}$ BRASIL. Superior Tribunal de Justiça. Resp. 1.412.433-RS. Apelante: Companhia Estadual de Distribuição de Energia Elétrica CEEE - RS. Apelada: Oady Chead Abrão. Relator: Min. Herman Benjamin. Brasília, 25 deAbril de 2018. Disponível em: https://www.stj.jus.br/docs internet/informativos/PDF/Inf0634.pdf.

Acesso em: 15 nov. 2020.
} 
consumo. Nesse sentido, há uma conformação com o Princípio da Razoabilidade da Administração Pública porque é irracional desencorajar o papel da concessionária em fiscalizar o sistema de controle de consumo por meio da estipulação de uma quantidade de meses consideravelmente grande no cálculo de dívida proveniente de consumo irregular. Ou seja, uma vez que as decisões estipulam mais de três meses nos cálculos dessa dívida, há o incentivo para que a concessionária não cumpra a fiscalização de forma periodicamente ideal. Além disso, uma vez que o princípio da finalidade da administração pública diz que o administrador deve buscar a satisfação do interesse público, é razoável que o cidadão tenha direito à menor desvantagem possível. Portanto, estipular mais de três meses, ao contrário do que vem sendo entendido pelo STJ, não se enquadra na busca da menor desvantagem possível ao cidadão posto que não se sabe o período real de consumo irregular, podendo haver um acréscimo de tempo que lesaria ele.

Diante disso, decisões do TJPE, como a Apelação Cível 0089539-13.2018.8.17.2001/PE, nem respeitam o Art. 927 do CPC, por não acatar as decisões de tribunais superiores, nem se adequam ao princípio da razoabilidade por levar em consideração os 6 últimos meses durante o cálculo da dívida proveniente de consumo irregular, como se vê a seguir:

Todavia, considerando que a concessionária afirma desconhecer o período em que a irregularidade ocorreu, a cobrança deve ser limitada aos 6 (seis) ciclos imediatamente anteriores ao da constatação da irregularidade. Inteligência do art. 132, $\S 1^{\circ}$, da Resolução n ${ }^{\circ} 414 / 2010$ ANEEL.4. Considerando que a cobrança administrativa levou em conta os 36 (trinta e seis) ciclos anteriores à data da descoberta da irregularidade, impõe-se a desconstituição parcial da dívida - e não total como consignado na sentença -, sendo válida, apenas, a dívida referente dos seis meses anteriores ao da comprovação do desvio de consumo. (BRASIL, 2020)

\section{A VULNERABILIDADE RESULTANTE DAS NORMAS SETORIAIS}

Conforme prevê a Resolução n. 414//2010 da ANEEL e, desde que observados os princípios constitucionais aplicáveis a sua atividade, a concessionária de serviço público pode cobrar por consumo de energia elétrica que deixou de ser registrado durante o período em que o medidor se encontrava em funcionamento irregular , sendo possível o lançamento da cobrança retroativa, por estimativa, referente à "energia não faturada". Entretanto, deve a concessionária oportunizar - de fato - ao consumidor o (i) acompanhamento efetivo do procedimento administrativo de vistoria do aparelho medidor de energia, bem como (ii) comprovar de forma inequívoca a autoria e a existência de irregularidade em razão de violação do aparelho de medição e a (iii) variação no consumo durante o período que é objeto de cobrança de recomposição. Pretende-se analisar cada um desses três requisitos neste momento, pois a grande maioria dos processos observados entre os meses de maio e julho deste ano, no TJPE, envolvendo o fornecimento de energia, faz referência a esse texto normativo. Desse modo, revela-se a importância de se investigar os elementos, os quais, geralmente, são considerados constitutivos de tal previsão legal.

$\mathrm{O}$ primeiro requisito (i) estabelece que o consumidor tem o direito a acompanhar efetivamente o procedimento administrativo de vistoria do aparelho medidor de energia. Em muitos dos processos judiciais analisados, as partes disputam sobre o que constitui o "acompanhamento efetivo". Para ilustrar isso, observa-se uma parte da apelação cível de número 001193-86.2018.8.17.2001/PE ${ }^{19}$, na qual a CELPE menciona que no caso dos autos, no TOI

${ }^{19}$ BRASIL. Tribunal de Justiça de Pernambuco. Apelação cível 001193-86.2018.8.17.200. Apelante: CELPE. 


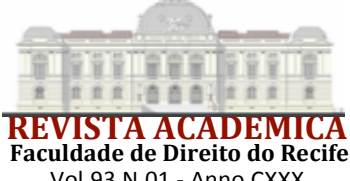

Vol.93 N.01 - Anno CXXX

consta que a inspeção foi acompanhada pelo inquilino, o que leva àconclusão de que o apelante respeitou o dispositivo da resolução da ANEEL, posto que a vistoria técnica ocorreu na presença da parte interessada.

Percebe-se, então, que a distribuidora entendeu que a mera "presença da parte interessada" durante a inspeção já constituiu o primeiro requisito apontado. Essa compreensão dificilmente pode ser sustentada de modo convincente como "acompanhamento efetivo", uma vez que o usuário, na maior parte das vezes, sequer tem o conhecimento técnico necessário para contrapor qualquer procedimento realizado pela perícia unilateral escolhida pela concessionária, demonstrando-se, assim, uma evidente falta de paridade de armas entre as duas partes.

Além disso encontra-se também um tanto equivocada, porque o texto normativo não suscita um "acompanhamento" puramente formal, no sentido de presenciar fisicamente o procedimento administrativo de vistoria, mas um "acompanhamento efetivo", o qual, portanto, requer que o consumidor tenha a possibilidade de influir durante o processo administrativo de produção do TOI, contemplando, assim, as exigências de um processo justo e isonômico de um Estado constitucional. Desse modo, acerta a decisão da apelação cível número 0002569 10.2018.8.17.2001/PEque aponta como unilateral a perícia que não atenda a essas exigências e que realizadadesacompanhada de perícia técnica vinculada a segurança pública e/ou a órgão metrológico oficial ${ }^{20}$, conforme regras do art. 129 , $\S \S$ e incisos da Resolução n. 414/2010, com a redação dada pela RES. ANEEL 479, de 03.04.2012.

À distribuidora, pois, é recomendável que conceda ao consumidor alguma oportunidade de influir na produção do documento TOI ou o produza acompanhada de uma perícia técnica vinculada a segurança pública e/ou órgão metrológico oficial, para que não seja impedida de "recuperar energia não faturada" em eventuais processos judiciais, os quais são bastante comuns.Ainda em se tratando do requisito (i), propomos uma leitura dele sob a perspectiva da teoria da perda de uma chance, a qual considera que aquele que, intencionalmente ou não, retira de outra pessoa a oportunidade de um dado benefício, responde por isso. Nesse sentido, quando a distribuidora não concede ao consumidor a oportunidade de influir na produção do TOI, nem realiza a perícia unilateral acompanhada de órgão metrológico oficial, ela faz com que o consumidor perca uma chance de provar eficientemente que não violou o aparelho medidor. Portanto, a concessionária deve responder por isso e, consequentemente, não poderá cobrar pela suposta energia não faturada, uma vez que não seguiu o procedimento adequado, prejudicando o usuário.

O segundo requisito (ii) estabelece que a concessionária deve comprovar de forma inequívoca a autoria e a existência de irregularidade em razão de violação do aparelho de medição. Em um número considerável de processos judiciais analisados, a distribuidora conseguiu comprovar, de modo adequado, a violação do aparelho de medição, mas não oferecia provas de que a irregularidade era devida a essa violação. Em consequência disso, a distribuidora teve sua pretensão de recuperar energia supostamente não faturada frustrada na ação cível número 0006244-75.2019.8.17.3090, uma vez que não foi capaz de comprovar a relação apontada:

Pugna pelo provimento do apelo a fim de que seja desconstituído o débito. Vejamos. Na hipótese, a cobrança impugnada corresponde a "diferença de energia não cobrada" em decorrência de "medição

Apelada: Kleber de Lima Vaz. Relator: Francisco Manoel Tenorio dos Santos. Disponível em:

https://srv01.tjpe.jus.br/consultaprocessualunificada/processo/. Acesso em: 30 nov. 2020.

${ }^{20}$ BRASIL. Tribunal de Justiça de Pernambuco. Apelação cível 0002569-10.2018.8.17.2001. Apelante: CELPE.

Apelada: Sebastiao Guedes da Silva Neto. Relator: Roberto da Silva Maia. Disponível em:

https://srv01.tjpe.jus.br/consultaprocessualunificada/processo/. Acesso em: 5 dez. 2020. 


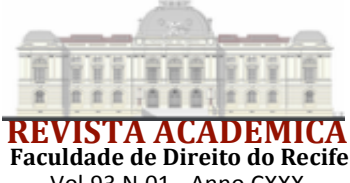

Faculdade de Direito do Recif

Vol.93 N.01 - Anno CXXX

violada", consoante se verifica da correspondência enviada pela recorrida ao apelante (ID 10947064, pág. 22). Ocorre, porém, que não há qualquer prova nos autos no sentido de que tal irregularidade tenha decorrido de fraude/irregularidade perpetrada pelo consumidor. (BRASIL, 2020)

Além de provar essa relação de causalidade necessária, para cumprir o segundo requisito, também é preciso que a inequívoca autoria do usuário seja corroborada. Nesse contexto, há o debate acerca do quanto a localização do medidor pode pôr em dúvida a autoria do consumidor em caso de violação desse aparelho, uma vez que, pergunta-se se é possível atribuir a violação do medidor ao consumidor mesmo que o aparelho esteja localizado fora de casa. Nesse caso, a norma setorial da ANEEL regulou o ponto, acabando com a controvérsia, estabelecendo que:

Art. 167. O consumidor é responsável: IV - pela custódia dos equipamentos de medição ou do TCCI da distribuidora, na qualidade de depositário a título gratuito, quando instalados no interior de sua propriedade. Parágrafo único. A responsabilidade por danos causados aos equipamentos de medição externa não pode ser atribuída ao consumidor, salvo nos casos de ação comprovada que lhe possa ser imputada. (ANEEL, 2012)

Quanto ao requisito terceiro (III), variação no consumo durante o período que é objeto de cobrança de recomposição, o mais objetivo deles, não há grandes controvérsias. Logo, esse mais os dois analisados anteriormente compõem o que é necessário para que a distribuidora tente recuperar energia não faturada, respeitando os direitos constitucionais e garantidos pelo CDC do usuário.

O duty to mitigate the loss ou o dever de mitigar a perda é um instituto importado do direito alienígena, mais precisamente da tradição Common Law, em que suas origens remontam a meados do século XVII. Tal instituto pode ser sintetizado em um princípio que exige que cada parte, de uma relação jurídica obrigacional, tanto nas relações contratuais quanto nas relações extracontratuais, empreenda esforços razoáveis para minimizar perdas. ${ }^{21}$ Esse instituto pode ser aplicado na relação consumidor e concessionária, a qual deve tentar recuperar a energia não faturada o mais célere possível para minimizar suas perdas, caso contrário poderá ser impedido de recuperá-las. Corrobora a aplicação desse dever o informativo 634 do STJ:

Na hipótese de débito estrito de recuperação de consumo efetivo por fraude no aparelho medidor atribuída ao consumidor , desde que apurado em observância aos princípios do contraditório e da ampla defesa , é possível o corte administrativo do fornecimento do serviço de energia elétrica, mediante prévio aviso ao consumidor, pelo inadimplemento do consumo recuperado correspondente ao período de 90 (noventa) dias anterior à constatação da fraude , contanto que executado o corte em até 90 (noventa) dias após o vencimento do debito, sem prejuízo do direito

\footnotetext{
${ }^{21}$ MARTINS, José Eduardo Figueiredo de Andrade. Dutytomitigatetheloss no direito civil brasileiro. São Paulo: [S.n.], 2014. Disponível em: https://www.teses.usp.br/teses/disponiveis/2/2131/tde-04102017-

20248/publico/dissertacao_FINAL_Jose_Eduardo_Figueiredo_de_Andrade_Martins.pdf. Acesso em: 17 dez. 2020.
} 


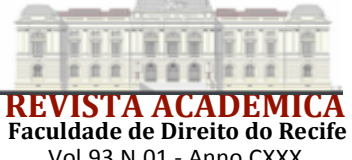

Vol 93 N.01 - Anno CXXX

de a concessionária utilizar os meios judiciais ordinários de cobrança da dívida, inclusive antecedente aos mencionados 90 (noventa) dias de retroação. (BRASIL, 2020).

\section{A FRAGILIDADE DA REGULAÇÃO CONSUMERISTA NA LEI DE CONCESSÕES}

Na pesquisa realizada no site de busca jurisprudencial do TJPE ${ }^{22}$, foram encontradas 28 decisões que citaram a Lei de Concessões desde o ano de 2005. Desses julgados, o Capítulo III daquela lei, que trata DOS DIREITOS E OBRIGAÇÕES DOS USUÁRIOS, foi suscitado em nenhum deles. Pode-se apontar, como um dos fatores responsáveis poresse problema, a pouca importância dada aos direitos e obrigações do consumidor na Lei No 8.987.

Embora o Código do Consumidor regule quaisquer relações consumeristas, há especificidades da concessão do fornecimento de energia responsáveis por dificultar a aplicação dele. Por exemplo, a regulação do setor energético implica a existência de normas setoriais e estas, apesar de contrárias aos princípios consumeristas em alguns momentos, são legitimadas porque o conteúdo técnico delas dificulta a visualização dessas violações. Diante disso, muitas vezes, os tribunais utilizam as normas setoriais como fundamentos das decisões sem se ater mais profundamente à efetivação dos direitos do consumidor, pois as normas setoriais alcançam um grau de especificidade mais alto que o CDC, passando a impressão de segurança quando, na verdade, resultam em assimetrias nas relações de consumo. Com isso, a fragilidade da Lei de Concessões se mostra determinante a esse cenário porque ela,ao se referir especificamente à concessão de serviços públicos, poderia ser responsável por elencar normas mais específicas do que as do $\mathrm{CDC}$, sendo capaz de tornar mais visíveis desconformidades aos princípios consumeristas nas normas setoriais.

Tal insuficiência se nota, por exemplo, a partir do momento que se vê apenas um artigo no que se refere ao capítulo III dos direitos e obrigações dos usuários, observando-se, por consequência disso, além de uma falta de densidade material, uma imprecisão na linguagem do texto. Nesse sentido, pode-se mencionar como exemplo o parágrafo II do Art. $7^{\circ}$, que estipula, como direito do usuário, receber do poder concedente e da concessionária informações para a defesa de interesses individuais ou coletivos. Como se nota, esse artigo não é capaz de sintaticamente impelir problemas como o da falta de informação do consumidor de energia. em relação, por exemplo, as modalidades tarifárias, que, como visto, assemelha-se a uma "ocultação de preços" porque é inespecífico e vago em demasia.

Portanto, a Lei de Concessão não demonstra possuir uma regulação no aspecto referente aos direitos do consumidor capaz de equilibrar as relações de consumo nos casos de concessão de serviços públicos. Em uma análise restrita à concessão do fornecimento de energia, ouso-me a sugerir que uma preocupação maior em relação ao parágrafo já mencionado concederia um certo protagonismo ao capítulo III da Lei de concessões, visto que um estabelecimento de um serviço adequado e a obrigação do usuário em levar ao conhecimento do poder público e da concessionária as irregularidades de que tenham conhecimento, mencionados nessa mesma lei, depende da informação do usuário e é justamente esse o escopo das normas protetivas do campo informativo do usuário.

Nesse sentido, alterar o parágrafo II do art. $7^{\circ}$ de "informações para defesa de interesses individuais e coletivos" a "informações para o exercício da vontade, reivindicação de serviços adequados, defesa de interesses individuais e coletivos" é um exemplo de como se poderia ampliar o campo de incidência do dever de informação. Incluindo-se, inclusive, o dever de informar sobre as modalidades tarifárias visto que isso se enquadra no escopo de possibilitar o exercício da vontade do consumidor, munindo-os de capacidade de escolha entre as modalidades

${ }^{22}$ Disponível em: https://www.tjpe.jus.br/servicos/jurisprudencia. Acesso em: 02 out. 2020. 
que mais o favorecem. Essa sugestão é apenas um exemplo entre as possibilidades de alteração que poderiam ser efetivas, visto que se poderia, também, disciplinar o livro III de acordo com os principais setores de concessão para que fosse estabelecida maior especificidade e clareza nas normas. Contudo, mudanças sutis, como a sugerida de início, já poderia ser capaz de abarcar mudanças significativas. Vale ressaltar que, no caso de disciplinar o livro III de acordo com os principais setores de concessão do serviço público, a matéria normativa deveria ser aquela cujo nível de especificidade não fosse tão geral quanto o CDC nem tão específico quanto às normas setoriais porque, ao contrário disso, constituir-se-ia uma espécie de paráfrase ou do código do consumidor ou das normas setoriais.

\section{CONCLUSÃO}

A partir deste artigo concluiu-se que, embora existam pontos de convergência, há outros de desconformidade entre o Código de Defesa do Consumidor e os contratos de concessão e de adesão de fornecimento de energia. Isso é corroborado por alguns fatores, como o fato de o arquivamento de reclamações, conforme dispõe o contrato de concessão, ter como fim apenas informar e divulgar, tendo uma efetividade duvidosa em um mercado caracterizado como um monopólio regulado; o fato de o contrato de concessão excluir como passíveis de penalidades os índices de segurança, havendo uma subpreocupação com o nível de risco ao qual está exposta a população e o fato de o conselho de consumidores, estipulado pelo contrato de concessão, ter apenas um caráter consultivo e opinativo além de apresentar um modelo de representatividade limitado. Além disso, no contrato de adesão, não se estipulaa obrigação de informar sobre outras tarifas não convencionaisas quais podem ser mais vantajosas ao consumidor, coisa que, na prática, se assemelha a uma espécie de ocultação de preços. Assim, a concretização do CDC nas relações de fornecimento de energia se vê prejudicada nesses aspectos.

Constatou-se, também,que a aceitação do TOI, por si só, é um dos casosmais visíveis e frequentes de mitigação ao $\mathrm{CDC}$ no âmbito judicial porque ele desrespeita o princípio consumerista da harmonização de interesses, já que é uma prova unilateral.Além disso, visualizou-se que fundamentações de decisões a partir do art. 132 da RES. n ${ }^{\circ}$ 414/2010 ocorreram em desconformidade com princípios constitucionais e decisões de tribunais superiores, lesando interesses dos consumidores. Nesse sentido, não só se constata a necessidade de regulação mais latente da relação de consumo pela Lei de Concessão de modo a sanar essas falhas, mas também se aponta a necessidade de novas análises acerca da influência da estrutura de produção normativa da própria ANEEL sobre a matéria das normas setoriais, as quais, por vezes, são problemáticas, como no caso do TOI e do mencionado art. 132, que se refere à estipulação do período de duração de consumo irregular.

\section{REFERÊNCIAS}

BRASIL. Constituição da República Federativa do Brasil de 1988. Institui um Estado Democrático. Brasília, DF: Presidência da República. Disponível em: http://www.planalto.gov.br/ccivil_03/constituicao/constituicao.htm. Acesso em: 22 out. 2020.

BRASIL.Contrato de Adesão Baixa Tensão. Contrato de prestação de serviço público de energia elétrica para unidades consumidoras atendidas em baixa tensão. Disponível em: http://www.agersa.ba.gov.br/wp-content/uploads/2021/01/CONTRATO-COELBA.pdf. Acesso em: 02 ago. 2020. 
BRASIL. Contrato de concessão de distribuição no 26/2000. Para distribuição de energia elétrica que celebram a União e a Companhia Energética de Pernambuco - CELPE. Agência Nacional de Energia Elétrica. Disponível

em:https://www.aneel.gov.br/documents/10184//15062917//Contrato+de+Concess\%C3\%A3o.pd f. Acesso em: 14 nov. 2020.

BRASIL. Lei n 10.406, de 10 de janeiro de 2002. Institui o Código Civil. Brasília, DF: Presidência da República. Disponível em:

http://www.planalto.gov.br/ccivil_03/leis/2002/110406compilada.htm. Acesso em: 16 nov. 2020.

BRASIL. Lei n⿳0 13.105, de 16 de Março de 2015. Código de Processo Civil. Brasília, DF: Presidência da República. Disponível em: http://www.planalto.gov.br/ccivil_03/_ato20152018/2015/lei/113105.htm. Acesso em: 21 nov. 2020.

BRASIL. Lein ${ }^{\circ}$ 8.078, de 11 de setembro de 1990. Dispõe sobre a proteção do consumidor. Brasília, DF: Presidência da República. Disponível em: http://www.planalto.gov.br/ccivil_03/leis/18078compilado.htm. Acesso em: 10 dez. 2020.

BRASIL. Lei $\mathbf{n}^{\mathbf{0}}$ 8.987, de 13 de fevereiro de 1995. Dispõe sobre o regime de concessão e permissão da prestação de serviços públicos previsto no art. 175 da Constituição Federal, e dá outras providências. Brasília, DF: Presidência da República. Disponível em:

http://www.planalto.gov.br/ccivil_03/LEIS/L8987compilada.htm. Acesso em: 14 set. 2020.

BRASIL. Portaria $\mathrm{n}^{\circ}$ 465, de 12 de dezembro de 2019. DiárioOficial [da] República

Federativa do Brasil. Poder Executivo, Brasília, DF, 16 dez. 2019. Seção 1, p. 156.

BRASIL. Resolução Normativa $\mathbf{n}^{\mathbf{0}}$ 414, de 09 de setembro de 2010. Estabelece as Condições Gerais de Fornecimento de Energia Elétrica. Disponível em:

https://www.aneel.gov.br/documents/656835/14876406/2016_ResolucaoNormativa4142010.pdf/ 5b1de1cd-d36f-4009-852a-8def3eeb0a4e. Acesso em: 27 jan. 2021.

BRASIL. Resolução normativa $n^{0}$ 451, de 27 de setembro de 2011. Estabelece as condições gerais para a criação, organização e funcionamento dos Conselhos de Consumidores de Energia Elétrica, no âmbito das concessionárias do serviço público de distribuição de energia elétrica; e revoga a Resolução ANEEL 138 de 10.05.2000. Disponível em:

http://www2.aneel.gov.br/cedoc/ren2011451.pdf. Acesso em: 03 dez. 2021.

BRASIL.Resolução normativa $\mathbf{n}^{\mathbf{0}}$ 479, de 03 de abril de 2012. Altera a Resolução Normativa $\mathrm{n}^{\mathrm{o}} 414$, de 9 de setembro de 2010, que estabelece as Condições Gerais de Fornecimento de Energia Elétrica de forma atualizada e consolidada. Disponível em:

https://www.aneel.gov.br/documents/656877/14486448/ren2012479.pdf/a89312fe-a5d7-415196be-95765ea2ce03?version=1.0. Acesso em: 03 jan. 2021.

BRASIL. Superior Tribunal de Justiça. Recurso Especial n 1645589-MS. Recorrente: HSBC BANK Brasil S.A. Recorrido: Nelida Doroteia Ormay. Relator: Ricardo Villas Bôas Cueva. Brasília, 04 de fevereiro de 2020. Disponível em:

https://processo.stj.jus.br/processo/pesquisa/?termo=Resp.+1.645.589\&aplicacao=processos.ea\& tipoPesquisa $=$ tipoPesquisaGenerica\&chkordem $=$ DESC\&chkMorto=MORTO. Acesso em: 12 nov. 2020. 
BRASIL. Superior Tribunal de Justiça. Resp. 1.412.433-RS. Apelante: Companhia Estadual de Distribuição de Energia Elétrica CEEE - RS. Apelada: Oady Chead Abrão. Relator: Min.

Herman Benjamin. Brasília, 25 de Abril de 2018. Disponível em:

https://www.stj.jus.br/docs_internet/informativos/PDF/Inf0634.pdf. Acesso em: 15 nov. 2020.

BRASIL. Supremo Tribunal de Justiça.Informativo $\mathbf{n}^{0} 0634$, de 06 de out. de 2018.

Fornecimento de energia elétrica. Débitos do consumidor. Fraude no medidor de consumo. Corte administrativo do serviço. Possibilidade. Critérios. Tema 699. Disponível em:

https://processo.stj.jus.br/jurisprudencia/externo/informativo/. Acesso em: 18 dez. 2020.

BRASIL. Tribunal de Justiça de Penambuco. Disponível em:

https://www.tjpe.jus.br/servicos/jurisprudencia. Acesso em: 15 dez. 2020.

BRASIL. Tribunal de Justiça de Pernambuco. Apelação cível no 0008764-77.2016.8.17.2810. Apelante: Celpe. Apelada: Mariluce Gomes Da Silva. Relator: Alberto Nogueira Virginio. Recife, 09 de junho de 2020. Disponível em:

https://srv01.tjpe.jus.br/consultaprocessualunificada/processo/. Acesso em: 22 nov. 2020.

BRASIL. Tribunal de Justiça de Pernambuco. Apelação cível 0002569-10.2018.8.17.2001. Apelante: CELPE. Apelada: Sebastiao Guedes da Silva Neto. Relator: Roberto da Silva Maia. Disponível em:https://srv01.tjpe.jus.br/consultaprocessualunificada/processo/. Acesso em: 05 dez. 2020.

BRASIL. Tribunal de Justiça de Pernambuco. Apelação cível 0006244-75.2019.8.17.3090. Apelante: Odair Gomes Correia. Apelada: CELPE. Relator: Jones Figueiredo Alves. Disponível em: https://srv01.tjpe.jus.br/consultaprocessualunificada/processo/. Acesso em: 05 dez. 2020.

BRASIL. Tribunal de Justiça de Pernambuco. Apelação cível 001193-86.2018.8.17.200. Apelante: CELPE. Apelada: Kleber de Lima Vaz. Relator: Francisco Manoel Tenorio dos Santos. Disponível em: https://srv01.tjpe.jus.br/consultaprocessualunificada/processo/. Acesso em: 30 nov. 2020.

BRASIL. Tribunal de Justiça de Pernambuco. Apelação Cível 0089539-13.2018.8.17.2001. Apelante: Claudia Souza da Silva. Apelada: Claudia Souza da Silva. Relator: Francisco Eduardo Goncalves Sertorio Canto. Disponível em:

https://srv01.tjpe.jus.br/consultaprocessualunificada/processo/00047609120198172001. Acesso em: 30 nov. 2020.

BRASIL. Tribunal de Justiça de Pernambuco. Apelação cível nº 0002722-91.2018.8.17.2470. Apelante: Maria de Fatima Pereira dos Santos. Apelado: CELPE. Relator: Agenor Ferreira de Lima Filho. Recife, 08 de junho de 2020. Disponível em:

https://srv01.tjpe.jus.br/consultaprocessualunificada/processo/. Acesso em: 15 nov. 2020.

BRASIL. Tribunal de Justiça de Pernambuco. Apelação Cível no 0004760-91.2019.8.17.2001. Apelante: Celpe. Apelada: Alexsandra Batista de Miranda. Relator: Francisco Eduardo Goncalves Sertorio Canto. Recife, 09 de junho de 2020. Disponível em: https://srv01.tjpe.jus.br/consultaprocessualunificada/processo/00047609120198172001. Acesso em: 28 out. 2020. 
BRASIL. Tribunal de Justiça de Pernambuco.Súmula TJPE n013. Disponível em:

https://www.tjpe.jus.br/documents/10180/0/-/08b9a5ff-0232-469a-bd24-d621219abf08. Acesso em: 18 dez. 2020.

BRASIL. Tribunal de Justiça do Rio de Janeiro.Súmula TJ nº 256, de 16 de jan. de 2012. Disponível em: http://www.tjrj.jus.br/documents/10136/31404/termo-ocor-irregularidade.pdf. Acesso em: 18 dez. 2020.

CAVALCANTI, Francisco et. al. (org.). História do Direito e do Pensamento Jurídico em Perspectiva. Recife: Ed. Atlas, 2012. 334 p.

FRIEDMAN, M. Capitalism and freedom. Chicago: University of Chicago Press, 1962.128 p.

GOMES, Rogério Zuel. A nova ordem contratual: pós-modernidade, contratos de adesão, condições gerais de contratação, contratos relacionais e redes contratuais. Revista de Direito do Consumidor, v.58, n. 58, 2006.

JUSTEN FILHO, Marçal. As diversas configurações da Concessão do serviço público. Revista de Direito Público da Economia, v.1, p. 95-136, 2003.

LENZ, Carlos Eduardo Thompson Flores. O contrato de concessão de serviço público. A\&CRevista de Direito Administrativo \& Constitucional, v. 8, n. 33, p. 161-192, 2008.

MARINO, Francisco Paulo de Crescenzo. Direito dos Contratos. São Paulo: Saraiva 2006. 38 p.

MARQUES, C. L. Contratos no Código de Defesa do Consumidor. São Paulo: Revista dos Tribunais, 2019.

MARTINS, José Eduardo Figueiredo de Andrade. Dutytomitigatetheloss no direito civil brasileiro. São Paulo: [S. n.], 2014. Disponível em:

https://www.teses.usp.br/teses/disponiveis/2/2131/tde-04102017-

120248/publico/dissertacao_FINAL_Jose_Eduardo_Figueiredo_de_Andrade_Martins.pdf. Acesso em: 17 dez. 2020.

MAZAGÃO, Mário, Natureza Jurídica da Concessão de Serviço Público. Revista de Doutrina da Quarta Região, São Paulo, 1933. 101 p.

MEDEIROS FILHO, Sólon. Fundamentos de Medidas Elétricas. Rio de Janeiro: Guanabara dois, 1981. $253 \mathrm{p}$.

NUSDEO, Ana Maria de Oliveira et al. (org.). Direito Econômico Regulatório. São Paulo: Saraiva, 2010.

ROSA, Taís Hemannda.O acesso à energia elétrica como manifestação do direito ao mínimo existencial: uma análise com ênfase na dimensão defensiva do direito de acesso à energia. Rio Grande do Sul: [S. n.], 2016. Disponível em:

https://repositorio.pucrs.br/dspace/handle/10923/8511. Acesso em: 17 dez. 2020.

ROUSSEAU, E. M. Análise Econômica do Direito. São Paulo: Atlas, 2015. 108 p. 